\title{
Minimal Invasive Flapless Piezotome Alveolar Crest Horizontal Split Technique: Preliminary Results
}

\author{
Stefano Scavia ${ }^{1}$, Rachele Roncucci ${ }^{2}$, Edoardo Bianco ${ }^{3}$, Marcello Maddalone ${ }^{4}$
}

\begin{abstract}
Introduction: Alveolar split crest is an established surgical technique to enable implant insertion into narrow and atrophic alveolar crest. This surgical technique is adopted to position standard or large implants so that postextractive anatomy compromises with this attempt. The aim of this study was to evaluate the horizontal alveolar bone augmentation and its stability along time with a minimally invasive flapless technique.

Materials and methods: Twenty-four implants were inserted in 10 patients during a 15-month period. Clinical parameters such as horizontal bone augmentation, intrasurgical complications, patient morbidity, implant loss, and vertical bone loss (VBL) were recorded in the first 3 years after surgery. Using cone-beam computed tomography (CBCT), alveolar bone width was measured for both implants position and bone reconstructions. 6 months later, at the time of implant integration, a new low-dose CBCT was performed. Implant survival (IS) and VBL were evaluated radiographically for 3 years.

Results: The initial bone thickness measured on the ridge is between $0.82 \mathrm{~mm}$ and $5.40 \mathrm{~mm}$ (average $2.43 \mathrm{~mm}$ ), after the split crest the bone width is between $4.65 \mathrm{~mm}$ and $8.09 \mathrm{~mm}$ (average $6.39 \mathrm{~mm}$ ). This leads to an increase in the alveolar bone width of between $0.80 \mathrm{~mm}$ and $6.01 \mathrm{~mm}$ (average $3.71 \mathrm{~mm}$ ) on the ridge. No implant was lost at 3 years, and all implants are stable at the end of the study. Three years after the surgery, controls showed a VBL of between $0.0 \mathrm{~mm}$ and $1.2 \mathrm{~mm}$ (average $0.63 \mathrm{~mm}$ ) around the inserted implants. These parameters suggest using a flapless technique to reduce bone resorption around the implant neck.

Conclusion: A minimally invasive approach allows to reduce the surgical trauma and postsurgical discomfort. The complete vascular supply is maintained, the bone resorption is reduced, and the connective epithelium does not undergo postsurgical retraction, achieving the full maintenance of the residual keratinized gingiva.

Clinical significance: A technique such as split crest can be a valid option to avoid autologous or heterologous bone grafts.

Keywords: Abfraction, Bone graft, Cone-beam computed tomography, Dental implants, Flapless surgery, Piezosurgery, Split crest.

The Journal of Contemporary Dental Practice (2020): 10.5005/jp-journals-10024-2743
\end{abstract}

\section{INTRODUCTION}

In the last few decades, different approaches were proposed in order to ameliorate dental treatments. ${ }^{1-9}$ The use of implants to rehabilitate maxillary and mandibular edentulous areas has become a common practice worldwide, with reliable long-term results. In different clinical situations, a lack of supporting bone as a result of physiologic bone rearrangement, surgical trauma, or delayed restoration, generates problems in implant insertions. As dental implants are to be inserted only if sufficient bone can adequately stabilize their position, bone augmentation procedures represent a natural and effective treatment option for these clinical situations. A lateral width of at least $1 \mathrm{~mm}$ around the implant bone crest at the buccal and palatal plane is required to achieve an adequate osseointegration and prevent lateral cortical thread's exposure. $^{10}$

Patients with long-standing edentulous arches, frequently associated with vertical and lateral extended bone resorptions, show bone spaces insufficient for safe implant placement in molar and premolar regions. Techniques for bone augmentation were proposed to bypass this problem, such as distraction osteogenesis, guided bone regeneration, osteoinduction, expansion using bone expanders or osteotomes, osteoconduction, revascularized bone, or split crest technique performed using ultrasound or conventional surgery. Most of them represent a difficult technical step, with a lot of possible complications, many times depending on technical
1,3,4 Department of Medicine and Surgery, University of Milano Bicocca, Monza, Italy

${ }^{2}$ University of Milan, Italy

Corresponding Author: Marcello Maddalone, Department of Medicine and Surgery, University of Milano Bicocca, Monza, Italy, Phone: +39 392333485, e-mail: edoardo.bianco13@gmail.com

How to cite this article: Scavia S, Roncucci R, Bianco E, et al. Minimal Invasive Flapless Piezotome Alveolar Crest Horizontal Split Technique: Preliminary Results. J Contemp Dent Pract 2020;21(1):28-35.

Source of support: Nil

Conflict of interest: None

skill of the surgeons or on the attitude of patient to follow pre- and postoperatory rules. ${ }^{11-13}$

Sometimes the results of different procedures could be wrong, with respect to presurgical status. Expansion using bone expanders or osteotomes and the split crest technique are today one of the most frequently used clinical choices for simplicity and reliability of outcomes. The second one consists of splitted vestibular and buccal cortical plates with displacement of the vestibular cortical bone, which will result in separating it from the bone marrow, creating an intermediate middle gap. This will be filled with autologous bone blocks or chips, particulate bone of human or animal origin, or other biomaterials like plasma derivatives, around the inserted implants.

() The Author(s). 2020 Open Access This article is distributed under the terms of the Creative Commons Attribution 4.0 International License (https://creativecommons. org/licenses/by-nc/4.0/), which permits unrestricted use, distribution, and non-commercial reproduction in any medium, provided you give appropriate credit to the original author(s) and the source, provide a link to the Creative Commons license, and indicate if changes were made. The Creative Commons Public Domain Dedication waiver (http://creativecommons.org/publicdomain/zero/1.0/) applies to the data made available in this article, unless otherwise stated. 
Ridge split procedures are executed using razor-sharp bone chisels, rotating or oscillating saws, the two devices are used together, or piezosurgical devices. Bone chisel traumatizes and could stress the patients during surgery, with the repeated hits made to separate the bone corticals. Rotating and oscillating instruments are time effective and of less stress but present more risks of damage to soft tissues around such as cheeks, lips, or tongue. $^{14}$

The use of piezosurgical devices for osteotomy is considered today as an advantageous alternative technique over conventional surgery. The use of ultrasound devices for medical diagnosis was first investigated in the middle of the last century. Nevertheless, ultrasonic devices were studied by following earlier works, and it is only in the last decades that piezosurgical cutters were commercially proposed for osteotomy and have become competent to conventional instruments in different applications. . $^{15,16}$

Ultrasound devices generate mechanical waves of frequencies greater than about $20 \mathrm{kHz}$. Although these frequencies can be produced by various means, that is, for ultrasonic dental scalers, most medical devices currently use the piezoelectric effect, which was found by Curie and Curie in $1880 .{ }^{17}$

Ultrasonic devices have the ability to cut mineralized hard tissues such as teeth or bone in a very safe and precise way, limiting damages to lateral tissues if adequately irrigated. ${ }^{18}$

At the same time, thanks to their ability to oscillate at the same speed and amplitude as the cutting tip, and the soft tissues such as nerves, blood vessels, or the Schneiderian membrane are not altered or destroyed by the cutting tips. This produces a safe and sure cut especially where these delicate anatomical structures are side placed at the surgical field. Moreover, surgical accuracy is facilitated by good visibility in the surgical field due to permanent irrigation of the same. Furthermore, piezoelectric cuts have been also reported to be more precise and to cause less splintering at the margin of the incision, and ultrasonic osteotomy allows modeled cuts that are almost impossible with rotating instruments or oscillating cutters. Few clinical studies have evaluated the clinical use of ultrasonic bone surgery in split expansion technique, showing satisfactory results in most of the cases. ${ }^{19-21}$

The aim of this work is to propose a minimally invasive technique for implant prosthetic rehabilitation, especially when there is a horizontal bone loss. A split crest surgical procedure is modified in order to allow a bone expansion and a concomitant implant insertion using a totally flapless method, both reducing the invasiveness of the treatment and at the same time preserving the mucous and vascular anatomy of the treated area. In fact, preservation of the subperiosteal blood microcirculation and the absence of bone vertical cuts seem to significantly reduce the vertical bone resorption that begins as a result of traditional split crest surgical procedures.

\section{Materials and Methods}

This study tested a one-step implant prosthetic rehabilitation with a flapless technique, in cases of severe horizontal bone atrophy with crestal bone thickness of around $1 \mathrm{~mm}$ or greater.

After a three-dimensional (3D) clinical examination, a virtual design of the insertion of the implants in a prosthetically guided position was made using a CBCT (Fig. 1).

Using digital radiographic processing software Romexis (Planmeca, Helsinki, Finland), horizontal measurement of bone thickness was performed at implant neck position on the crestal ridge.

In all patients, the same protocol was followed for surgery and implant insertion. Subjects received oral hygiene treatment and instructions during the days prior to the intervention. Antibiotics ( $1 \mathrm{~g}$ of amoxicillin plus clavulanic acid) were prescribed to the patient for 6 days, starting 1 day before implant installation. If necessary, one tablet of midazolam $7.5 \mathrm{mg}$ was administered 20 minutes before the intervention to promote patient relaxation and facilitate his or her collaboration.

Before surgery, 1-minute rinses with chlorhexidine digluconate $0.20 \%$ were recommended. Lips and perioral area were also cleaned with Betadine. An infiltrative anesthesia (articaine $40 \mathrm{mg} / \mathrm{mL}$ and epinephrine $0.01 \mathrm{mg} / \mathrm{mL}$ ) was applied to all patients from vestibular and lingual directions. After the surgery, patients were encouraged to take, in case of pain, ibuprofen ( $600 \mathrm{mg} / 8$ hours). If the pain persisted, patients were also advised to come to the dental office for counseling.

Under local anesthesia, crestal mucotomies were performed at implant preparation sites. The position of the implants was calculated on a 3D software, based on the principles of prosthetically guided implantology; through surgical guides the implant position is copied in the bone. The buccal/lingual width of the mucotomy must not exceed the crestal bone thickness detected in the same position, and the mesio/distal length of the mucotomy is in relation to the planned implant diameter (usually $3 \mathrm{~mm}$ for implants of 3.5-4 mm diameter).

Using this criterion, circular mucotomies were made on alveolar bone ridges with a thickness of more than $3 \mathrm{~mm}$. However, on ridges of lower width, mucotomies were, therefore, made with a rectangular-shaped mucotomic scalpel, whereas in cases where the thickness corresponds to a millimeter or less, individual straight incisions were made of $3 \mathrm{~mm}$ length in the mesial distal sense, which is identified as the total flapless access (Fig. 2).

After the excision of the mucosa, a sagittal osteotomy of a depth of about $1 \mathrm{~mm}$ was outlined in the cortical bone exposed using a sharp piezoelectric insert no. OT2 (Mectron, Carasco, Italy) (Fig. 3).

After that the sagittal osteotomic cut was deepened with a $0.25 \mathrm{~mm}$ diameter piezoelectric micro-saw insert no. OT12s (Mectron, Carasco, Italy) toward apical direction, at a depth equivalent to the planned implant length. In the cases of multiple adjacent implants, the osteotomic cuts were connected to the mesial and distal submucosal portion of the sites corresponding to the mucous opercula, linking the different incisions. In these cases, the crestal incisions must be on the same sagittal bone line in order to favor the connection while maintaining the osteotomic axis unchanged. The separation of the vestibular and lingual cortices in the area corresponding to the implant insertions was extended with the same technique for about $3-4 \mathrm{~mm}$ in the mesial and distal direction, without involving the root surface of the adjacent natural dental elements.

When the bone cuts were completed, the ridges were separated in a lingual/buccal direction using bone osteotomes and chiselshaped expanders with pointed section mounted and activated by magnetic and dynamic equipment (Sweden \& Martina, Due Carrare PD, Italy) (Fig. 4).

Once the first horizontal expansion was achieved, with a space gain of between $1.5 \mathrm{~mm}$ and $2 \mathrm{~mm}$ inside the corticals, insertion was made at the sites of implant with a second expansion of increasing circular diameter osteotomes mounted on the magnetodynamic 


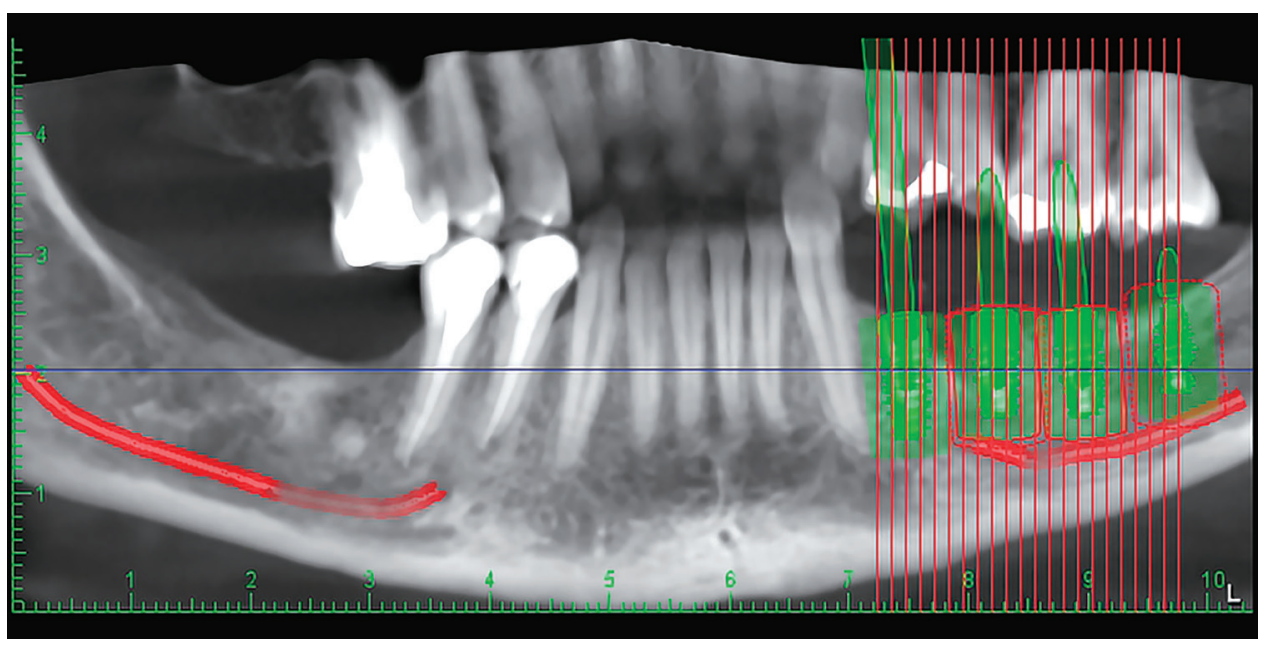

Fig. 1: Virtual design of the insertion of the implants performed by software
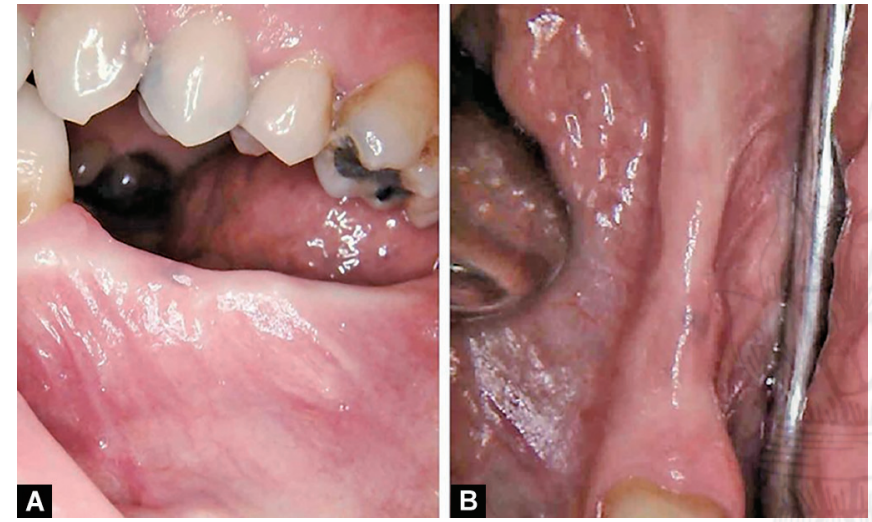

Figs $2 \mathrm{~A}$ and $\mathrm{B}$ : Clinical case: thin edentulous ridge

device. When in the crestal portion, a circular expansion was obtained at the implant insertion sites corresponding to the diameter of the implants to be inserted, and the preparation was completed in its apical portion with implant kit tips. The cortex separation was maintained and stabilized using bone expanders of variable diameters (Bone Expanders; Mectron, Carasco, Italy). The expanders were progressively replaced by the insertion of bone-level implants, until the complete insertion of all the planned ones, and the head of fixtures were closed with healing screws. In cases where the mesial and distal intercortical residual space to the inserted implants was greater than $2 \mathrm{~mm}$, it was filled with slowresorption biomaterial of a grain size between $0.25 \mathrm{~mm}$ and $1.0 \mathrm{~mm}$ Bio-Oss small (Geistlich Pharma, Wolhusen, Switzerland). In multiple rehabilitations, in order to obtain a correct insertion of the bone graft, the remaining gingival portion between the mucotomies was gently displaced using microsurgical clamps for tissues.

While performing crestal mucotomies, the soft tissues removed were deepithelialized and the residual connective tissues were modeled and inserted to cover the exposed portions of the biomaterial. The connective grafts were subsequently blocked against the connective layer of the adjacent mucosa through the insertion of the transmucosal healing screws, and no sutures were used. Postsurgical and pharmacological instructions were then delivered to the patient and is first checked 15 days after the surgery. At that time, the transmucosal screws were removed, cleaned of any plaque residues and, once the correct integration of the connective tissue grafts was verified, the screws reinserted in place. Furthermore, indications to restore toothbrushing and oral hygiene prescriptions were newly given to the patient (Fig. 5).

Patients were reviewed 30 days after the operation and again after 6 months. At the time of the last check, i.e., after 6 months, a new low-dose CBCT (Planmeca, Helsinki, Finland) was performed to verify the bone expansion obtained and its stabilization. After that, the complete prosthetic rehabilitation is achieved. Measurements were performed on 24 implants placed in 10 patients at time 0 (before surgery) and at time 1 (6 months after surgery, before prosthetics). The width of the bone crest at time 0 and at time 1 was measured using ProMax 3D CBCT with superimposition of scans every $1.1 \mathrm{~mm}$ (Fig. 6).

The dental scan cuts were processed in the same anatomical position both on radiographs and at the implant insertion sites. For each site, the horizontal bone thickness was measured at the site of the implant neck, the values were processed, and the horizontal bone gain obtained is then calculated.

Additional measurements at T0 and T1 were made at the midpoint and apex of the implant. Crowns were inserted and annual radiographic checks were scheduled. Periapical X-rays were made with a centering device and parallel technique 3 years after the operation, and the VBL was measured by means of Romexis digital software mesially and distally at the neck of the implant. The custom-made apparatus used for standardization of the radiographic exposures was fabricated by incorporating a Rinn $X-C-P$ film holder with a polyvinyl siloxane impression material (Aquasil Ultra®; Dentsply Sirona, NY, USA).

\section{Results}

A group of 10 patients aged between 38 years and 75 years was recruited for this study, and a total number of 24 bone level implants were inserted over a period of 15 months using the method previously illustrated. Low-dose CBCT performed 6 months after the surgery shows an horizontal increase in bone thickness.

All patients underwent periodontal treatment, if requested prior to surgery and for the duration of the study, and the 24 implants were inserted in the absence of complications or adverse events. 

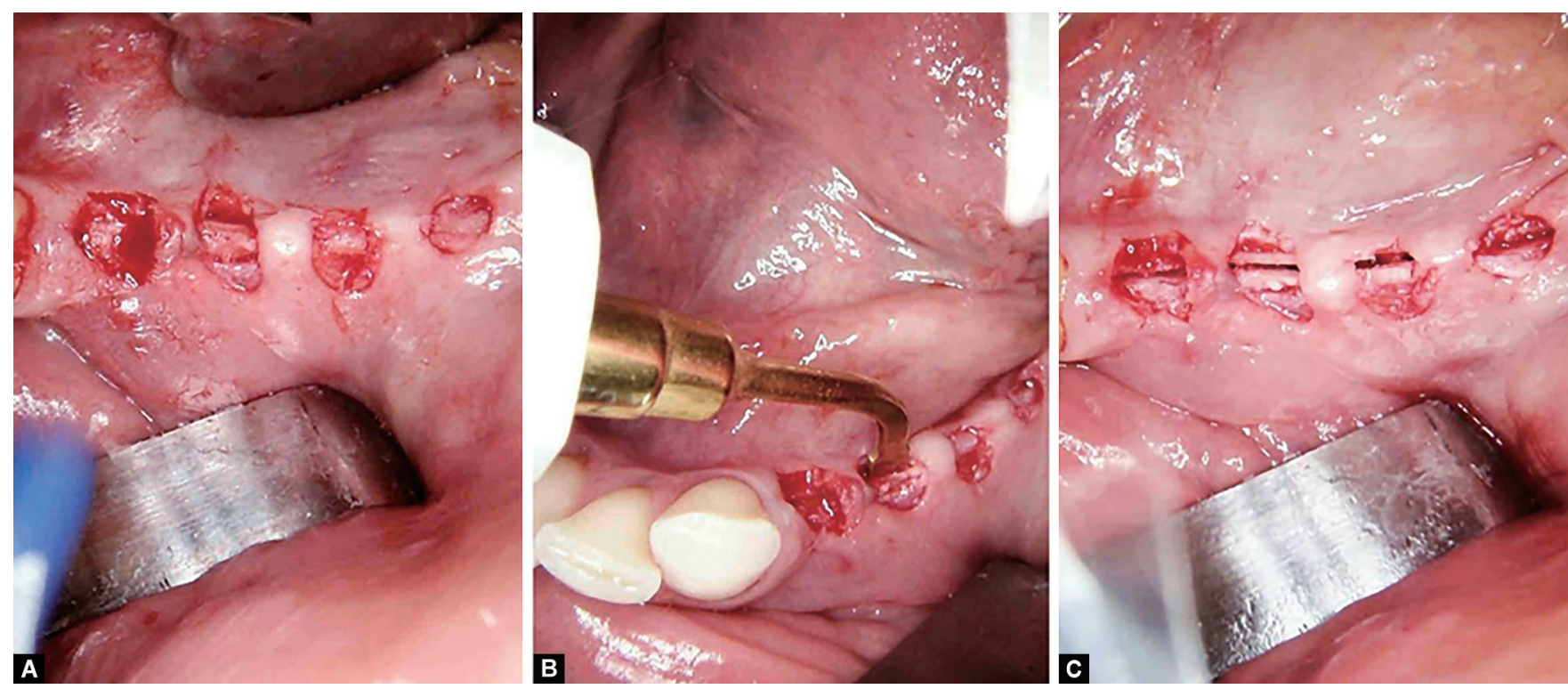

Figs $3 \mathrm{~A}$ to $\mathrm{C}$ : Crestal mucotomies performed at implant preparation sites and sagittal osteotomy outlined in the cortical bone
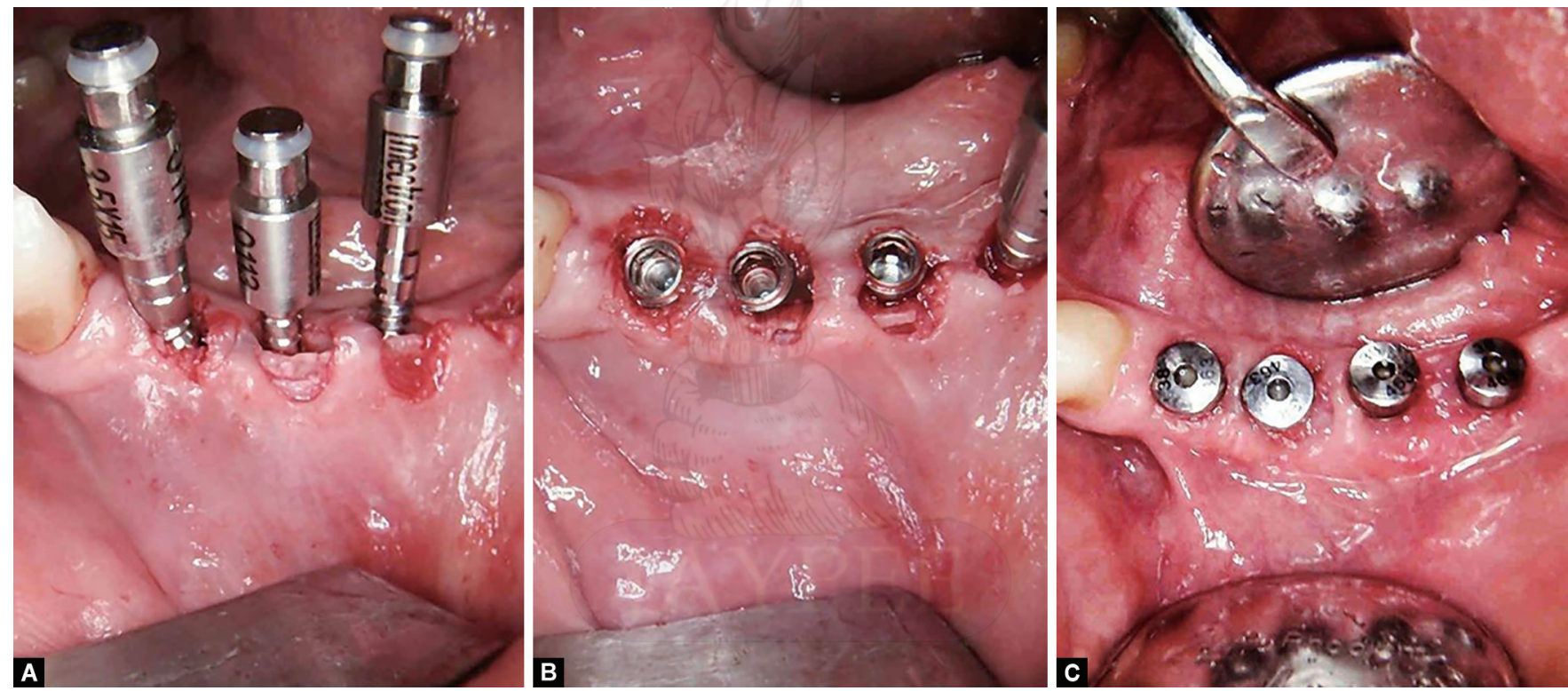

Figs 4A to C: Ridges separated in a lingual/buccal direction using bone osteotomes-chisel-shaped expanders, implant positionment, and healing

Before the operation, the amplitude of the alveolar process corresponding to the implant insertion site measured between $0.82 \mathrm{~mm}$ and $5.40 \mathrm{~mm}$ (average $2.43 \mathrm{~mm}$ ); while at 6 months after the surgery, with implant osseointegration, the width was between $4.65 \mathrm{~mm}$ and $8.09 \mathrm{~mm}$ (average $6.39 \mathrm{~mm}$ ). This resulted in an increase in crestal bone width of between $0.80 \mathrm{~mm}$ and $6.01 \mathrm{~mm}$ (average $3.71 \mathrm{~mm}$ ) measured at the implant neck.

Annual checks scheduled after surgery and prosthetic restoration confirmed the survival of all the implants, and, therefore, the IS rate was $100 \%$.

Three years after the operation, the digital orthogonal intraoral plate performed with Rinn centering on all patients showed a vertical mesial and distal bone loss of between $0.0 \mathrm{~mm}$ and $1.2 \mathrm{~mm}$ (average $0.63 \mathrm{~mm}$ ) at the implant neck (Table 1).
Bone thickness at half of the implant length and apex was also recorded at $\mathrm{T} 0$ and $\mathrm{T} 1$ (Table 2 ).

\section{Discussion}

The split crest technique in cases of horizontal bone atrophy associated with immediate implant insertion was described in different papers. ${ }^{22}$

The alveolar bone remodeling and its possible partial fracture trigger in the period following the surgery reshaping phenomena were able to induce a significant VBL of implant support. According to the data presented in the literature, this reabsorption seems to be proportional to the initial bone thickness and to the horizontal volumetric increase obtained using this technique. Some authors 
associate a guided bone regeneration procedure to limit problems linked to a split bone technique. ${ }^{23}$

Subsequent studies seem to demonstrate a reduction in vertical bone reshaping and resorption resulting from the split crest technique avoiding vertical bone cuts and maintaining the cortical blood supply and subperiosteal blood. Therefore, surgical solutions with flaps of partial thickness or flapless type have been proposed in the literature. ${ }^{11,24,25}$

Furthermore, the use of piezoelectric surgery reduces the invasiveness of the split crest treatment, which was traditionally performed using rotating and manual mechanical instruments, resulting in less trauma to the patient and a more conservative

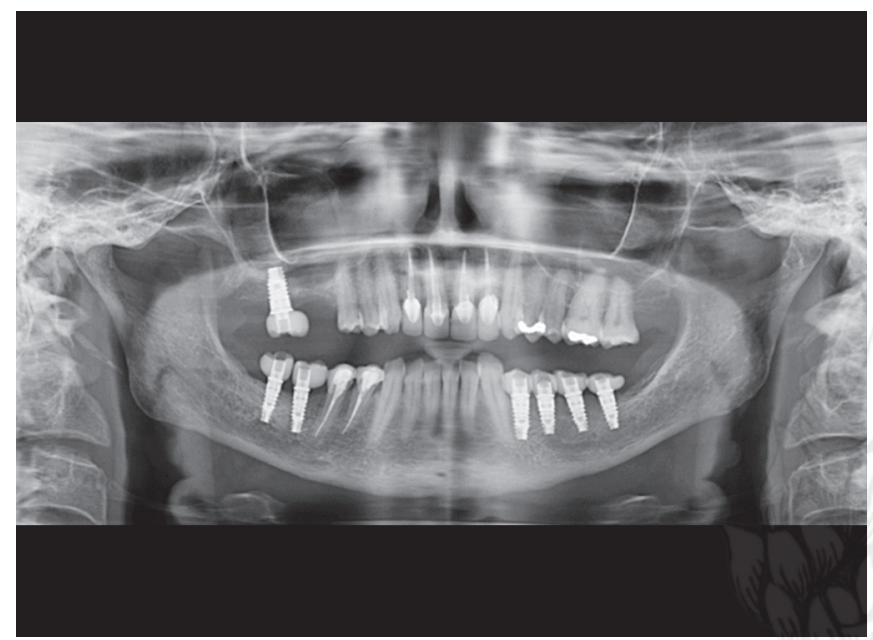

Fig. 5: Crown placement approach to hard tissues with a consequent reduction in the loss of the supporting vertical bone. ${ }^{21,26}$

Preservation, conditioning, and eventual increase in periimplant keratinized gingival tissue through connective tissue grafting techniques further improve prognosis and preservation of alveolar bone support following bone expansion techniques. ${ }^{27}$

Based on these data, the patients of the present study were treated with a minimally invasive technique of horizontal bone augmentation using a split crest piezoelectric-assisted osteotomy technique. All patients underwent periodontal therapy as early as 2 weeks before the surgery and throughout the assessment period (3.5-5 years). Furthermore, all patients followed the standard postoperative instructions, with particular attention to the hygiene of transmucosal healing screws.

The reduction in mucosal access, proportional to the initial thickness of the bone crest, allowed optimal preservation of the residual keratinized tissue. The connective tissue graft, where a circular or ovoid-shaped mucotomy has been performed, was fixed without the use of sutures. In this way, the peri-implant mucous thickness showed improvement and improving at the same time the hygiene of the surgical wound (plaque accumulation risk or food residues were reduced in the absence of sutures). Subsequently to surgery and up to the end of the evaluation period, the patients showed a good general level of oral hygiene and the health status of the peri-implant mucous tissue was also good.

The conditioning of the postoperative mucous tissue plays an important role in cases of major atrophy (bone thickness $<2.5 \mathrm{~mm}$ ), in which an ovoid mucotomy or total flapless access is used; it is initially induced through the transmucosal screws and subsequently with the temporary and/or definitive restoration. The cortical separation through ultrathin $(0.25 \mathrm{~mm}$ and wedge shaped)

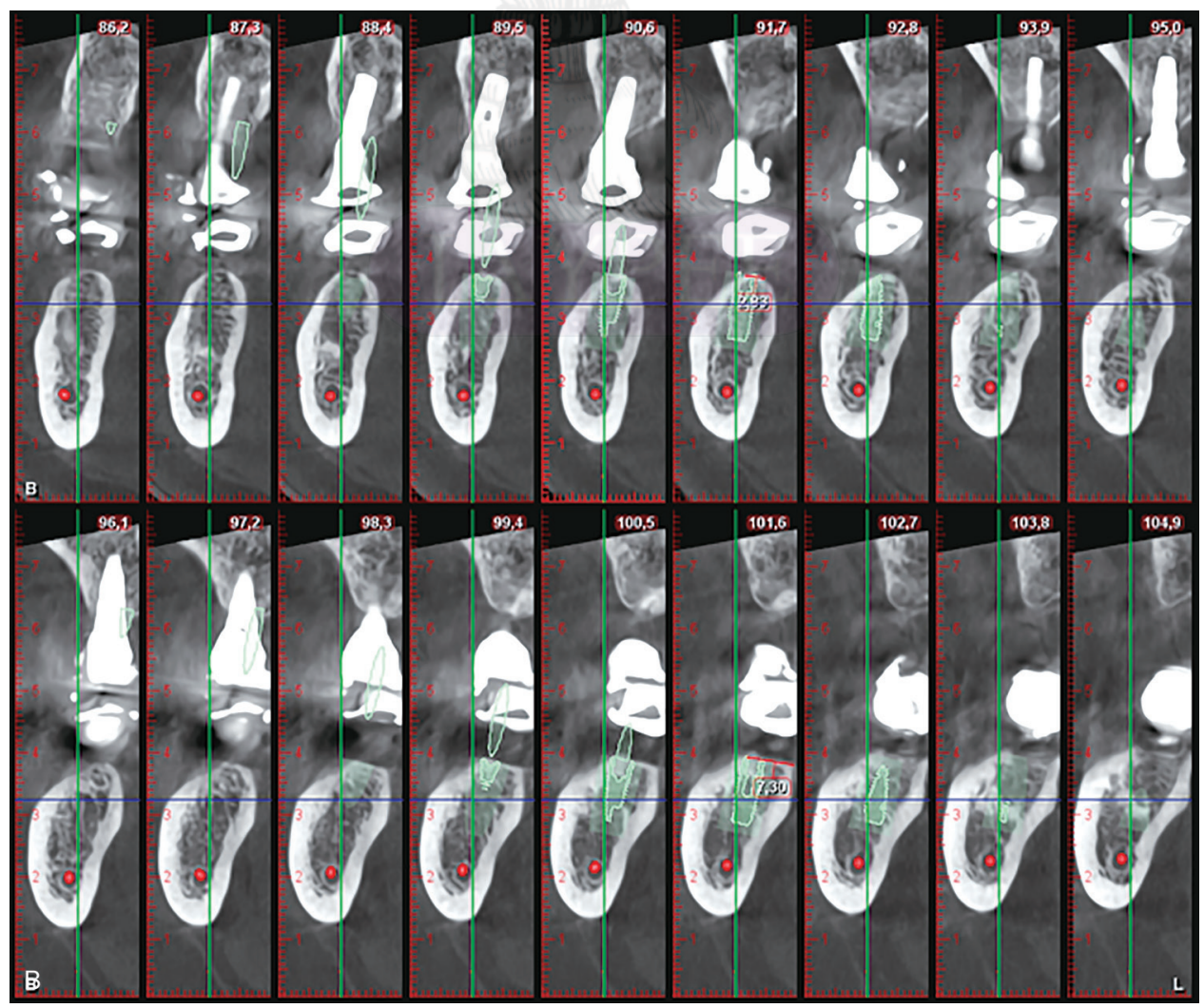

Fig. 6: Measurements before surgery 
Alveolar Crest Horizontal Split Technique

\begin{tabular}{|c|c|c|c|c|c|c|}
\hline Patient & Implant position & $S B W(m m)$ & $F B W(\mathrm{~mm})$ & $B W G(\mathrm{~mm})$ & $3 Y V B L-M(\mathrm{~mm})$ & $3 Y V B L-D(\mathrm{~mm})$ \\
\hline 1 & 46 & 2.11 & 6.00 & 3.89 & 0.6 & 0.7 \\
\hline 1 & 47 & 2.12 & 5.20 & 3.08 & 0.7 & 0.5 \\
\hline 2 & 34 & 3.75 & 7.00 & 3.25 & 1.0 & 1.0 \\
\hline 2 & 35 & 2.25 & 7.21 & 4.96 & 1.0 & 1.1 \\
\hline 2 & 36 & 1.50 & 7.50 & 6.00 & 1.1 & 1.2 \\
\hline 2 & 37 & 3.00 & 6.26 & 3.26 & 1.0 & 0.9 \\
\hline 3 & 41 & 1.60 & 5.22 & 3.62 & 0.4 & 0.4 \\
\hline 3 & 43 & 4.42 & 5.22 & 0.80 & 0.1 & 0.0 \\
\hline 3 & 45 & 1.80 & 5.60 & 3.80 & 0.2 & 0.2 \\
\hline 4 & 35 & 3.22 & 5.53 & 2.31 & 0.0 & 0.1 \\
\hline 5 & 36 & 3.81 & 6.40 & 2.59 & 0.3 & 0.5 \\
\hline 6 & 46 & 3.16 & 5.60 & 2.44 & 0.5 & 0.5 \\
\hline 7 & 27 & 1.20 & 5.85 & 4.65 & 0.9 & 1.1 \\
\hline 8 & 36 & 2.83 & 5.73 & 2.90 & 0.4 & 0.5 \\
\hline 8 & 37 & 5.30 & 8.09 & 2.79 & 0.5 & 0.4 \\
\hline 9 & 26 & 5.40 & 8.64 & 3.24 & 0.0 & 0.1 \\
\hline 10 & 17 & 1.20 & 6.00 & 4.80 & 0.7 & 0.8 \\
\hline 10 & 15 & 1.26 & 5.09 & 3.83 & 0.6 & 0.6 \\
\hline 10 & 13 & 0.82 & 4.65 & 3.83 & 1.0 & 1.0 \\
\hline 10 & 11 & 1.08 & 7.09 & 6.01 & 1.1 & 1.2 \\
\hline 10 & 21 & 2.72 & 6.77 & 4.05 & 0.8 & 0.8 \\
\hline 10 & 23 & 1.08 & 5.73 & 4.65 & 0.7 & 0.8 \\
\hline 10 & 25 & 1.22 & 5.30 & 4.08 & 0.5 & 0.7 \\
\hline 10 & 27 & 1.60 & 6.28 & 4.68 & 0.7 & 0.8 \\
\hline
\end{tabular}

SBW, starting bone width; FBW, final bone width; BWG, bone width gain; 3YVBL-M, 3 years' vertical bone loss-mesial; 3 YVBL-D, 3 years vertical bone loss-distal

Table 2: Bone thickness at half of the implant length and apex

\begin{tabular}{|c|c|c|c|c|c|}
\hline Patient & Implant position & $\begin{array}{l}\text { Starting middle bone } \\
\text { width }(\mathrm{mm})\end{array}$ & $\begin{array}{l}\text { Starting apex bone } \\
\text { width }(\mathrm{mm})\end{array}$ & $\begin{array}{l}\text { Final middle bone width } \\
(\mathrm{mm})\end{array}$ & Final apex bone width $(\mathrm{mm})$ \\
\hline 1 & 46 & 6.60 & 9.49 & 6.60 & 9.80 \\
\hline 1 & 47 & 9.40 & 9.82 & 9.82 & 10.60 \\
\hline 2 & 34 & 5.62 & 7.39 & 6.80 & 7.60 \\
\hline 2 & 35 & 5.42 & 7.42 & 6.00 & 7.01 \\
\hline 2 & 36 & 6.93 & 7.70 & 6.85 & 8.54 \\
\hline 2 & 37 & 8.92 & 8.41 & 10.01 & 8.73 \\
\hline 3 & 41 & 8.20 & 13.20 & 8.60 & 14.21 \\
\hline 3 & 43 & 8.00 & 11.00 & 9.00 & 11.20 \\
\hline 3 & 45 & 8.40 & 9.00 & 9.61 & 10.20 \\
\hline 4 & 35 & 8.01 & 9.41 & 9.41 & 9.35 \\
\hline 5 & 36 & 8.60 & 11.22 & 9.40 & 12.01 \\
\hline 6 & 46 & 10.99 & 10.99 & 10.80 & 11.00 \\
\hline 7 & 27 & 9.75 & 12.91 & 11.43 & 13.21 \\
\hline 8 & 36 & 10.92 & 13.08 & 11.26 & 13.06 \\
\hline 8 & 37 & 14.20 & 15.58 & 14.28 & 15.26 \\
\hline 9 & 26 & 11.80 & 11.82 & 12.08 & 11.53 \\
\hline 10 & 17 & 7.10 & 14.61 & 7.61 & 14.81 \\
\hline 10 & 15 & 4.04 & 11.74 & 5.57 & 14.60 \\
\hline 10 & 13 & 5.25 & 7.47 & 4.94 & 9.66 \\
\hline 10 & 11 & 4.94 & 9.39 & 7.52 & 10.02 \\
\hline 10 & 21 & 7.28 & 12.34 & 8.24 & 10.77 \\
\hline 10 & 23 & 4.68 & 8.80 & 5.58 & 8.18 \\
\hline 10 & 25 & 3.22 & 6.02 & 5.34 & 6.26 \\
\hline 10 & 27 & 7.20 & 14.40 & 6.87 & 15.90 \\
\hline
\end{tabular}


piezoelectric inserts allows a precise and extremely conservative cortical separation compared to the use of traditional mechanical rotary instruments, as stated by Vercellotti and Nevins. ${ }^{28}$

Bone expansion, initially carried out on the sagittal axis, leads to a cortical distancing of up to $2 \mathrm{~mm}$ avoiding vertical osteotomies or fracture of the alveolar cortical walls. A single sagittal osteotomy, connected below the gingival tissue in the case of adjacent multiple implant sites, allows a better achievement of this result while respecting the integrity of the overlying mucous tissue.

Subsequently the circular deformation that completes the preparation for the implant insertion allows to obtain consistent horizontal expansions, from $0.8 \mathrm{~mm}$ up to $6 \mathrm{~mm}$ (average $3.71 \mathrm{~mm}$ ), containing the traumatism of the cortical bone components. Furthermore, the use of a slow-resorption biofunctional bone substitute seems to compensate for the phenomena of alveolar bone reshaping. ${ }^{29}$

The grafting of a heterologous material based on hydroxyapatite (Bio-Oss small, Geistlich Pharma, Wolhusen, Switzerland), inserted in the intracortical space, after the horizontal expansion, appeared as one of the keys to the success of this technique. It was distributed mesially and distally to the implant fixtures, below the mucous tissue, and acting as a conductive substrate favorable to the regeneration of new bone within the space created through the split crest technique. The radiographic evaluation at 3 years showed a lower VBL, measured mesially and distally to the implant neck, when compared with the data in the literature and the traditional flap technique. The traditional approach involves the exposure of the surgical site through the detachment of a full-thickness mucoperiosteal flap and the subsequent suture with the acceptance of mucous margins and an healing by first intention. Longoni et al. report a mean mesial VBL of $2.5( \pm 0.6 \mathrm{~mm})$ for transmucosal implants and 2.4 ( $\pm 0.5 \mathrm{~mm}$ ) for submerged implants, a distal loss of 2.7 ( $\pm 0.5 \mathrm{~mm})$ for transmucosal implants and $2.3( \pm 0.6 \mathrm{~mm})$ for submerged ones, at 3 years. ${ }^{30}$

The data collected from the present study report a 3-year preimplant vertical bone deficiency (mesial and distal) ranging from $0.0 \mathrm{~mm}$ to $1.2 \mathrm{~mm}$ (average $0.63 \mathrm{~mm}$ ). All cases were performed in a period of 15 months and implants evaluated for at least 36 months after loading. ${ }^{31,32}$ No implant failures were recorded and the conditions of the implants and the surrounding soft and hard tissues support safety and reliability of the surgical procedure. The results of this study promote the use of a minimally invasive ultrasonic split technique for implant placement in patients with narrow or atrophic bone ridges.

\section{CONCLUSION}

The technique of horizontal bone augmentation through split crest is less invasive if performed flapless compared to the traditional surgical procedure.

The preservation of the blood supply from the periosteum above the split crest bone portion and the absence of vertical bone incisions seem to confirm a stable horizontal volume increase within 6 months. A reduction in the vertical resorption of the maxillary cortex was obtained if compared with the standard flap approach in the first 3 years.

Intraoperative trauma and postsurgical discomfort were reduced with a minimally invasive technique. This surgical approach seems to be predictable and easier to accept by the patient with less cooperation, reducing at the same time the risk of complications.
Finally, this technique is operator dependent, especially in the most important horizontal atrophies in which the total-flapless protocol is used. The limited number of cases treated claims for further studies.

\section{References}

1. Jafarian M, Mirhashemi FS, Emadi N. Finite element analysis of stress distribution around a dental implant with different amounts of bone loss: an in vitro study. Dent Med Probl 2019;56(1):27-32. DOI: 10.17219/ $\mathrm{dmp} / 102710$

2. Venino PM, Citterio CL, Pellegatta $A$, et al. A micro-computed tomography evaluation of the shaping ability of two nickel-titanium instruments, HyFlex EDM and ProTaper next. J Endod 2017;43(4): 628-632. DOI: 10.1016/j.joen.2016.11.022.

3. Świder K, Dominiak M. Er:YAG and diode laser application in implant bed preparation and implant uncovering: a case report. Dent Med Probl 2019;56(1):111-116. DOI: 10.17219/dmp/100386.

4. Maddalone M. The association between the psychological status and the severity of facial deformity in orthognathic patients. Angle Orthod 2012;82(3):396-402. DOI: 10.2319/060211-363.1.

5. Maddalone M, Gagliani M, Citterio $\mathrm{CL}$, et al. Prevalence of vertical root fractures in teeth planned for apical surgery. A retrospective cohort study. Int Endod J 2018;51(9):969-974. DOI: 10.1111/iej.12910.

6. Porcaro G, Busa A, Bianco E, et al. Use of a partial-thickness flap for guided bone regeneration in the upper jaw. J Contemp Dent Pract 2017;18(12):1117-1121. DOI: 10.5005/jp-journals-10024-2186.

7. Bianco E, Rota D. Oral findings in Rett syndrome: an update and review of the literature. Dent Med Probl 2018;55(4):441-445. DOI: 10.17219/ dmp/99203.

8. Bianco E, Maddalone M, Porcaro G, et al. Treatment of osteoradionecrosis of the jaw with ozone in the form of oil-based gel: 1-year follow-up. J Contemp Dent Pract 2019;20(2):270-276. DOI: 10.5005/jp-journals-10024-2508.

9. Koç N, Çağırankaya LB. Investigation of the determinants of the mandibular cortical morphology. Dent Med Probl 2019;56(1):21-25. DOI: $10.17219 / \mathrm{dmp} / 102262$.

10. Nedir R, Bischof M, Briaux JM, et al. A 7-year life table analysis from a prospective study on ITI implants with special emphasis on the use of short implants. Results from a private practice. Clin Oral Implants Res 2004;15(2):150-157. DOI: 10.1111/j.1600-0501.2004.00978.x.

11. Scipioni A, Bruschi GB, Calesini G. The edentulous ridge expansion technique: a five-year study. Int J Periodontics Restorative Dent 1994;14(5):451-459.

12. Chiapasco M, Zaniboni M, Rimondini L. Dental implants placed in grafted maxillary sinuses: a retrospective analysis of clinical outcome according to the initial clinical situation and a proposal of defect classification. Clin Oral Implants Res 2008;19(4):416-428. DOI: 10.1111/j.1600-0501.2007.01489.x.

13. Jensen SS, Terheyden $\mathrm{H}$. Bone augmentation procedures in localized defects in the alveolar ridge: clinical results with different bone grafts and bone-substitute materials. Int J Oral Maxillofac Implants 2009;24(Suppl):218-236.

14. Blus C, Szmukler-Moncler S. Split-crest and immediate implant placement with ultra-sonic bone surgery: a 3-year life-table analysis with 230 treated sites. Clin Oral Implants Res 2006;17(6):700-707. DOI: 10.1111/j.1600-0501.2006.01206.x.

15. Horton JE, Tarpley Jr TM, Wood LD. The healing of surgical defects in alveolar bone produced with ultrasonic instrumentation, chisel, and rotary bur. Oral Surg Oral Med Oral Pathol 1975;39(4):536-546. DOI: 10.1016/0030-4220(75)90192-9.

16. Horton JE, Tarpley Jr TM, Jacoway JR. Clinical applications of ultrasonic instrumentation in the surgical removal of bone. Oral Surg Oral Med Oral Pathol 1981;51(3):236-242. DOI: 10.1016/0030-4220(81)90051-7.

17. Curie J, Curie P. Contractions et dilatations produites par des tensions dans les cristaux hémièdres à faces inclinées. CR Acad Sci Gen 1880;93:1137-1140. 
18. Vercellotti T, De Paoli S, Nevins M. The piezoelectric bony window osteotomy and sinus membrane elevation: introduction of a new technique for simplification of the sinus augmentation procedure. Int J Periodontics Restorative Dent 2001;21(6):561-567.

19. Harder S, Wolfart $S$, Mehl C, et al. Performance of ultrasonic devices for bone surgery and associated intraosseous temperature development. Int J Oral Maxillofac Implants 2009;24(3): 484-490.

20. González-García A, Diniz-Freitas M, Somoza-Martín M, et al. Ultrasonic osteotomy in oral surgery and implantology. Oral Surg Oral Med Oral Pathol Oral Radiol Endod 2009;108(3):360-367. DOI: 10.1016/j. tripleo.2009.04.018.

21. Vercellotti T. Piezoelectric surgery in implantology: a case report - a new piezoelectric ridge expansion technique. Int J Periodontics Restorative Dent 2000;20(4):358-365.

22. Sethi $A$, Kaus T. Maxillary ridge expansion with simultaneous implant placement: a 5-year result of an on going clinical study. Int J Oral Maxillofac Implants 2000;15(4):491-499.

23. Simion M, Baldoni M, Zaffe D. Jawbone enlargement using immediate implant placement associated with a split-crest technique guided tissue regeneration. Int J Periodontics Restorative Dent 1992;12(6):462-473.

24. Scipioni A, Bruschi GB, Calesini G, et al. Bone regeneration in the edentulous ridge expansion technique: histologic and ultrastructural study of 20 clinical cases. Int J Periodontics Restorative Dent 1999;19(3):269-277.
25. Brugnami F, Caiazzo A, Mera P. Piezosurgery-assisted, flapless split crest surgery for implant site preparation. J Maxillofac Oral Surg 2014;13(1):67-72. DOI: 10.1007/s12663-012-0377-3.

26. Danza M, Guidi R, Carinci F. Comparison between implants inserted into piezo split and unsplit alveolar crests. J Oral Maxillofac Surg 2009;67(11):2460-2465. DOI: 10.1016/j.joms.2009.04.041.

27. Studer S, Naef R, Scharer P. Adjustment of localized alveolar ridge defects by soft tissue transplantation to improve mucogingival esthetics: a proposal for clinical classification and an evaluation of procedures. Quintessence Int 1997;28(12):785-805.

28. Vercellotti T, Nevins ML, Kim DM, et al. Osseous response following resective therapy with piezosurgery. Int J Periodontics Restorative Dent 2005;25(6):543-549.

29. Araùjo $M$, Lindhe J. The influence of Bio-Oss collagen on healing of an extraction socket. An experimental study in dogs. Int J Periodontics Restorative Dent 2008;28(2):123-135.

30. Longoni S, Maroni I, Baldini A, et al. Retrospective radiographic study of marginal bone changes of 88 implants placed with split crest technique in the maxillary latero-posterior area. Journal of Osseointegration 2016;8(1):8-13. DOI: 10.23805/jo.2016.08.01.02.

31. Galluzzi F, Pignataro L, Maddalone M, et al. Recurrences of surgery for antrochoanal polyps in children: a systematic review. Int J Pediatr Otorhinolaryngol 2018;106:26-30. DOI: 10.1016/j.jporl.2017.12.035.

32. Ambu E, Citterio CL, Pellegatta $A$, et al. The use of limited CBCT in the early diagnosis of root vertical fracture: a case report. Glob J Oral Sci 2018;4:18-24. DOI: 10.30576/2414-2050.2018.04.4. 